\title{
Photoelectron Photoion Coincidence Spectroscopy to Unveil Reaction Mechanisms by Isomer-selective Detection of Elusive Molecules: From Combustion to Catalysis
}

\author{
Patrick Hemberger ${ }^{\S}$ and Andras Bodi \\ §SCS-DSM Award for best poster presentation in Catalysis Science \& Engineering
}

\begin{abstract}
Elusive and reactive intermediates, such as radicals, play a central role in reaction mechanisms. Photoelectron photoion coincidence spectroscopy with tunable vacuum ultraviolet synchrotron radiation offers a multiplexed, sensitive, mass- and isomer-selective way to identify and, in some cases, determine mole fractions of reactive species. It thus helps to unveil the missing link(s) between reactants and products. After a brief overview of the technique, we review two systems in three different reactive environments. First, the unimolecular decomposition mechanism of ortho-xylyl radicals is revealed in pyrolysis experiments. Second, the insights gained are used to analyze a fuel-rich meta-xylene flame, which suggests that important xylyl isomerization reactions are currently missing in combustion models. Third, photoion mass-selected threshold photoelectron spectra identify the fulvenone ketene as the crucial intermediate in the catalytic fast pyrolysis of a lignin model compound and help map heterogeneous catalysis mechanisms.
\end{abstract}

Keywords: Photoelectron spectroscopy · Pyrolysis · Reaction mechanism · Reactive intermediates · Vacuum ultraviolet synchrotron radiation

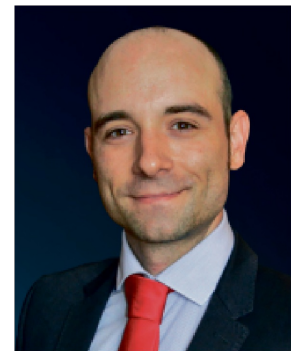

Patrick Hemberger obtained his $\mathrm{PhD}$ in physical chemistry from University of Würzburg, Germany on the photoionization of radicals and carbenes with synchrotron radiation and optical lasers. He joined Paul Scherrer Institute as a beamline scientist in 2011 and is currently also principal investigator in a Swiss Federal Office of Energy (BFE) project about combustion chemistry. His research interests are reac-

${ }^{*}$ Correspondence: Dr. P. Hemberger Laboratory for Femtochemistry and Synchrotron Radiation

Paul Scherrer Institute, $\mathrm{CH}-5232$ Villigen

E-mail: patrick.hemberger@psi.ch tion dynamics and mechanisms in high-energetic environments such as combustion and catalysis. To unveil these insights, he probes reactive molecules isomer-selectively using vacuum ultraviolet synchrotron radiation, ultrafast lasers, combined with photoelectron spectroscopy and mass spectrometric techniques.

\section{Introduction}

Combustion is here to stay: even after discounting automotive uses, it is responsible for almost $50 \%$ of the energy consumption in Switzerland.[1] Thus, we have to address its downsides, such as greenhouse gas, $\mathrm{NO}$ and soot emissions. Apart from the engineering approach to pursue advanced motor and exhaust concepts, such as homogeneous charge compression ignition (HCCI), or selective catalytic reduction (SCR), harmful emissions may be also mitigated with the help of a fundamental understanding of combustion chemistry and kinetics. Such knowledge also helps to settle abatement strategies and introduce emission standards. ${ }^{[2]}$ Combustion is initiated by free radical reactions, and ignition is particularly sensitive to the radical concentrations. A detailed knowledge of the radical concentrations is therefore imperative to develop predictive combustion models for established and alternative fuels. Standard chemical analysis techniques, e.g. gas chromatography combined with mass spectrometry (GC/MS), only detect stable species, due to long sample residence times and rapid quenching of elusive species.

Molecular beam ${ }^{[3]}$ mass spectrometry (MS) coupled with vacuum ultraviolet (VUV) synchrotron radiation has emerged as a versatile tool to trace transient species formed in gas-phase ${ }^{[4]}$ reactions in flames, ${ }^{[5]}$ reactors ${ }^{[6]}$ and heterogeneously catalyzed processes directly. ${ }^{[4 b, 7]}$ Thanks to the rapid expansion into high vacuum, high dilution in an inert buffer gas and adiabatic cooling, quenching processes can be greatly suppressed. ${ }^{[3]}$ Dissociative ionization can be controlled by tuning the photon energy between $5-30 \mathrm{eV}$, or $250-41$ $\mathrm{nm}$ when recording photoionization mass spectra (PIMS). The energy dependence of PIMS allows us to distinguish, e.g. methyl ions formed by direct ionization of methyl radicals from those formed by fragmentation of ionized methane. Fig. 1 shows PI spectra of meta- and para-xylyl (methylbenzyl) radicals in blue. Although the different ionization onsets, $6.9 \mathrm{vs}$. $7.0 \mathrm{eV}$, suf- 
Fig. 1.

Photoionization spectra (in blue) and threshold photoelectron spectra (in black) of meta- and para-xylyl radicals. In contrast with the slowly rising PIMS, offset by the difference in ionization energy, isomer-specific vibrational transitions are clearly evident in the TPES and can be modeled by calculating Franck-Condon factors (in red).

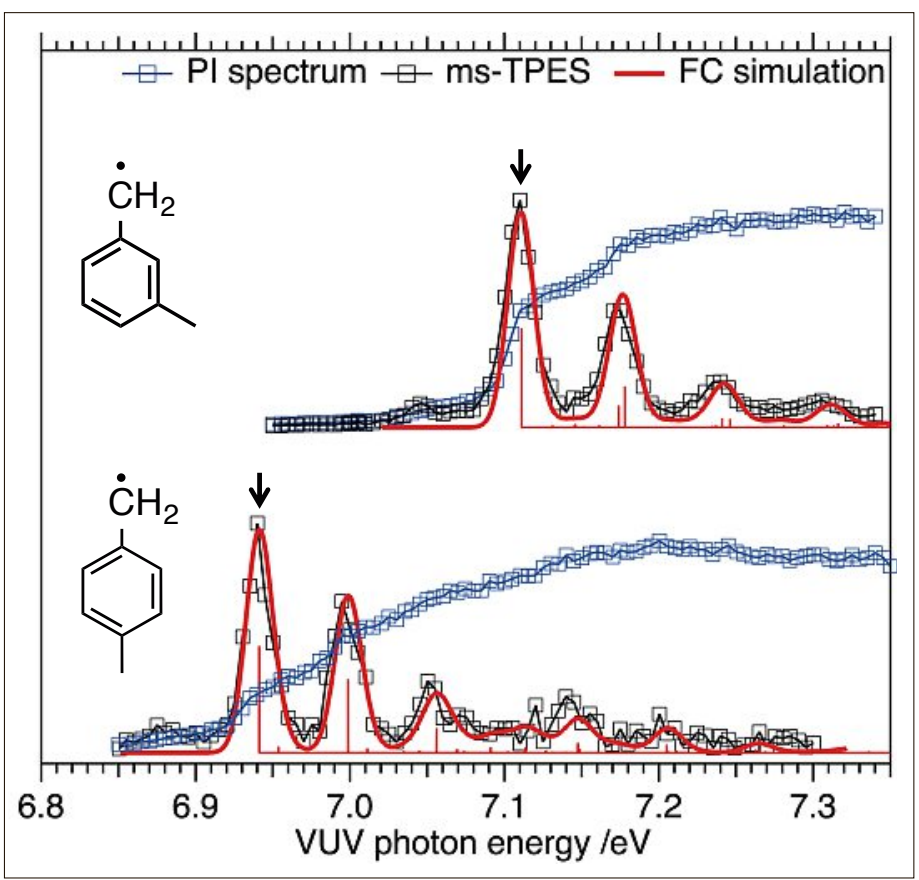

fice to identify pure samples when combined with state-of-the-art calculations, the lack of spectral features make it difficult to characterize mixtures or identify constitutional isomers if the ionization energies are close by. Since combustion environments often contain a plethora of species, this limits the selectivity of PIMS.

\section{Photoion Photoelectron Coincidence Spectroscopy}

Imaging photoelectron photoion coincidence spectroscopy (iPEPICO) can be used to recover the necessary spectral selectivity to address this issue by virtue of photoelectron spectroscopy. Photoelectrons are velocity map imaged and detected according to their velocity on a fast position sensitive detector. The most easily tunable VUV sources, synchrotrons, deliver quasi-continuous light and the promptly detected electron also acts as start signal for the time-of-flight mass analysis of the coincident photoion. By correlating threshold (near-zero kinetic energy) photoelectrons with ions from the same ionization event, photoion massselected threshold photoelectron spectra (ms-TPES) are obtained. This additional analytical dimension is highly beneficial because vibrational transitions follow the Franck-Condon (FC) principle, i.e. are governed by the nuclear wave function overlap of the initial neutral and final ion state. Thus, ms-TPE spectra constitute an isomer-specific spectroscopic fingerprint and can easily be simulated.

In Fig. 1, TPE spectra of meta- and para-xylyl radicals are presented in black along with FC simulated photoelectron spectra. The activity of a ring deformation mode upon ionization is nicely reproduced by the FC simulation and used together with the adiabatic ionization energy (arrows) for the assignment of each individual isomer.

PEPICO was originally developed by Brehm and von Puttkammer to investigate the unimolecular dissociation of ions. ${ }^{[8]}$ It has been improved continuously as a spectroscopic tool and to map the phase space and the flow of reactive flux in internal energy selected ions. ${ }^{[9]}$ Imaging PEPICO experiments are found at third-generation synchrotron facilities, ${ }^{[10]}$ where they are used to investigate chiral systems, ${ }^{[10 b]}$ to derive highly accurate thermochemistry, ${ }^{[11]}$ to understand impulsive and statistical fragmentation processes and map complex fragmentation pathways. ${ }^{[12]}$ Despite low number densities and difficult preparation, PEPICO has been used to record photoelectron spectra of numerous shortlived radical species at high intensity light sources, including the VUV beamline at the Swiss Light Source, for more than a decade. ${ }^{[13]}$ These spectra now serve to detect elusive species directly in high-energy environments like flames and reactors or to gain insight into their thermochemistry. ${ }^{[14]}$ For instance, accurate heats of formation were obtained for reactive $m$-xylylene diradicals (7 in Scheme 1) as well as for photolytically produced methyl peroxy species. ${ }^{[15,16]}$

Furthermore, the high energy resolution, dynamic range, and fragment-free ionization make PEPICO a universal, sensitive and selective analytical tool for the isomer-selective detection of elusive gas-phase intermediates in complex reactive environments. ${ }^{[10 \mathrm{c}, 17,18]}$ Here, we would like to present two recent topics in detail. First, xylene flame chemistry was studied by following the fate of xylyl radicals upon unimolecular decomposition and in a fuel-rich xylene flame. Second, thanks to detecting the fulvenone intermediate, we could establish the catalytic fast pyrolysis mechanism of guaiacol, a lignin model compound.

\section{Pyrolysis and Combustion}

Aromatic compounds represent more than $45 \mathrm{vol} \%$ in conventional fuels, and are responsible for the high octane ratings in modern gasoline. Due to health issues, benzene is regulated in fuels in Europe and the US ${ }^{[19]}$ and is replaced by toluene and xylenes. It is widely accepted that xylenes form xylyl radicals $\left(\mathrm{C}_{8} \mathrm{H}_{9}\right)$ upon fuel decomposition in internal combustion engines. However, questions arose about the potentially divergent reactivity of the three xylyl isomers.[20] Kinetic experiments in shock tubes ${ }^{[21]}$ supported the conclusion that ortho- (2, Scheme 1) and para-xylyl (4) decompose by hydrogen atom loss at a much faster rate than meta-xylyl (3). Evidently, elementary reactions, such as fuel destruction pathways, need to be fully understood to develop predictive combustion models. Pyrolysis reactors (see Scheme 1) are ideally suited to investigate the thermal decomposition of reactive molecules. ${ }^{[22]}$ Xylylbromides $\left(\mathrm{C}_{8} \mathrm{H}_{9} \mathrm{Br}, \mathbf{1 a}, \mathbf{b}, \mathbf{c}\right.$ see Scheme 1) produce xylyl radicals $\mathbf{2}, \mathbf{3}$, 4 isomer-selectively upon thermal decomposition. ${ }^{23]}$ The gas sample leaves the hot micro reactor (Scheme 1) ${ }^{[22 a]}$ forms a molecular beam, which is ionized by incident VUV radiation and both ions and electrons are detected.

Threshold photoelectron spectra in Fig. 1 confirm the isomer-selective generation of $m$ - and $p$-xylyl radicals at $m / z$ $=105$, based on their different vibrational fingerprints. With the help of their distinctly different ms-TPES, the fate of the fuel radicals can be followed isomer-selectively as a function of the reaction temperature. As the temperature increases in the reactor, hydrogen atom loss is observed to yield $m / z=104$ (shown for $o$-xylyl in Fig. 2a) and the corresponding ms-TPE spectra provide the necessary isomer information (see Fig. 2b). At low reactor temperatures, $o$-xylylene (5) and benzocyclobutene (8) are observed at $m / z=104$. The reaction mixture changes fundamentally above $1000 \mathrm{~K}$ (upper trace in Fig. 2b): $o$-xylylene $(5)$ is depleted, and $p$-xylylene (6) and styrene (9) are identified as additional components (Scheme 1). While formation of $o$-xylylene (5) and benzocyclobutene (8) is explained by hydrogen loss and a subsequent ring closure reaction, ${ }^{[23,24]}$ styrene 


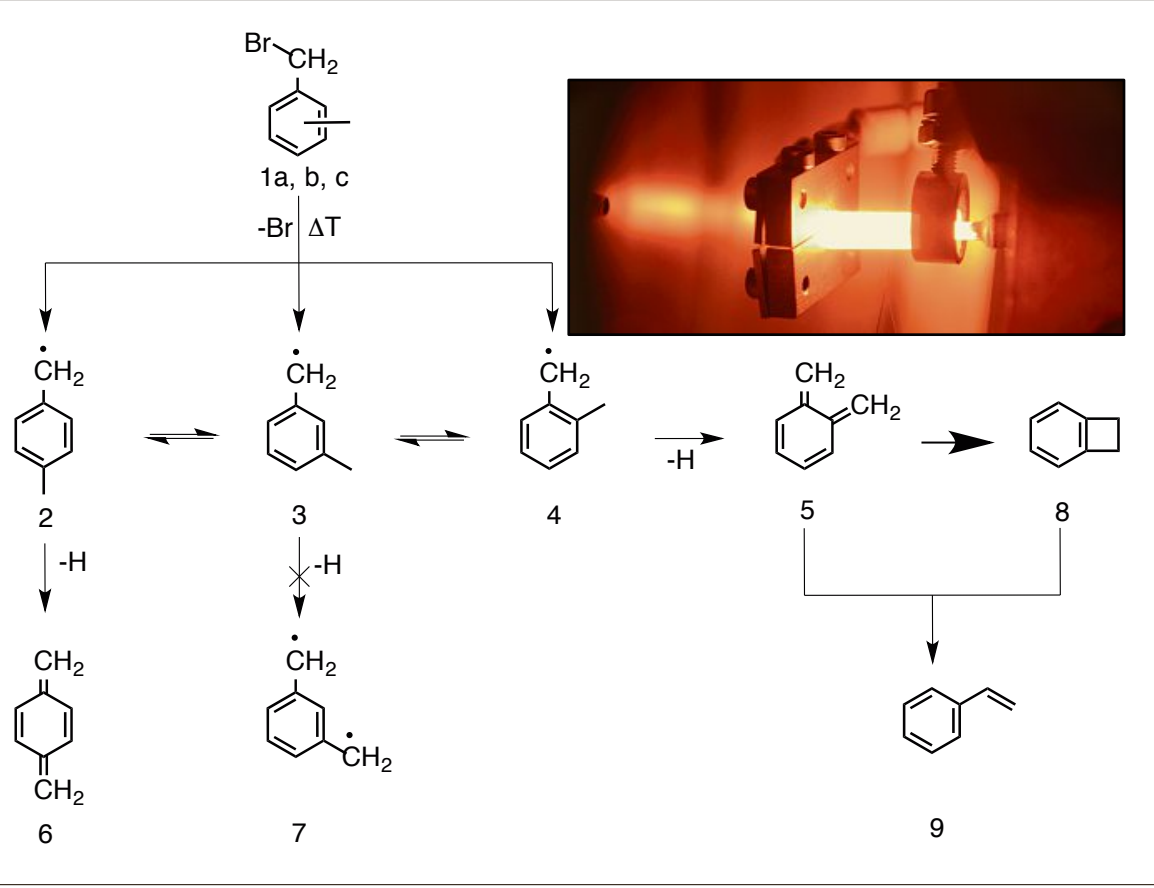

Scheme 1. Decomposition of xylyl radicals upon pyrolysis and in model flames.

(9) and p-xylylene (6) generation can be rationalized by calculating the $\mathrm{C}_{8} \mathrm{H}_{8}$ potential energy surface which connects 9 and $\mathbf{5}$ over a carbene intermediate. ${ }^{[23]}$ Production of 6 can be explained by an equilibration of the xylyl radical at very high temperatures and subsequent hydrogen atom loss (Scheme 1). However, note the absence of the H-loss product from $m$-xylyl, to be discussed later. Although these processes are purely unimolecular, the underlying chemistry is already quite complex and photoelectron photoion coincidence spectroscopy, supported by $a b$ initio calculations, could identify the reaction mechanism leading to combustion-relevant radical intermediates and products.

Combustion processes represent a complex interplay between a plethora of chemical reactions and fluid dynamics. Therefore, the importance of unimolecular reactions, such as the xylyl mechanism, may be questioned as far as the decomposition of radical intermediates in actual flames is concerned. In a collaboration with the University of Duisburg/Essen and the German Aerospace Center, we coupled a McKenna-type burner, operated at $c a .40$ mbar, to the PEPICO apparatus to study flames directly (see Fig. 3b). ${ }^{[25]}$ Thanks to the low pressure, the flame zone is stretched and a quartz glass sampling cone is used to continuously sample from the flame (see Fig. 3b). ${ }^{[4 b, 26]}$ A molecular beam is formed here, too, which preserves reactive intermediates.

Different flame zones are sampled in height above burner scans by moving the sampling cone with respect to the burner surface, probing the reactant fuel and oxy- the threshold ionization matrix, in which the threshold electron signal is plotted as a function of photon energy and coincident photoion $m / z$ ratio. The ms-TPE spectrum and FC simulation of $m / z=104$ (Fig. 3, center) reveals $p$-xylylene (6), benzocyclobutene (8) and styrene (9) in the flame environment, while the $m$-xylylene diradical (7) was generally absent. Nonetheless, a neat $m$-xylyl pyrolysis experiment, analogous to the one shown in Fig. 2 for $o$-xylyl, revealed the same composition of reactive $\mathrm{C}_{8} \mathrm{H}_{8}$ isomers, which implies that the same chemistry drives these processes both in pyrolysis and in the flame. ${ }^{[29]}$ While ortho-4 and para-xylyl (2) putatively lose hydrogen by simple $\mathrm{C}-\mathrm{H}$ bond cleavage, the same reaction would lead to a diradical 7 in the case of the meta isomer 3. ${ }^{\text {[24b] }}$ Da Silva et al. suggested, based on calculations, that $m$-xylyl (3) first rearranges to the ortho- $\mathbf{2}$ or para-isomer $\mathbf{4}$ prior to hydrogen atom loss. ${ }^{[28]}$ Thereafter, stable species, $e . g$. p-xylylene (6), benzocyclobutene (8) and styrene (9) are yielded. ${ }^{[23,24 b, 28]}$ This may also explain the reduced reactivity and the slower burning velocity of $m$-xylene.

Height above burner scans can be employed to determine the concentration profiles of reactive intermediates directly (see Fig. 3b,c). ${ }^{[30]}$ Fig. 3c compares the experimental mole fraction of $m$-xylyl as a function of the height above burner with five different combustion models shown in dashed lines. ${ }^{[31]}$ Interestingly, the concentration of the fuel radical is overestimated by all kinetic models, which may indicate that the isomerization channel, also found upon pyrolysis of the radicals, plays an important role in flames. ${ }^{[29]}$

Xylyl radicals are relatively inactive towards oxidation due to their aromatic character, and can generate polycyclic aromatic

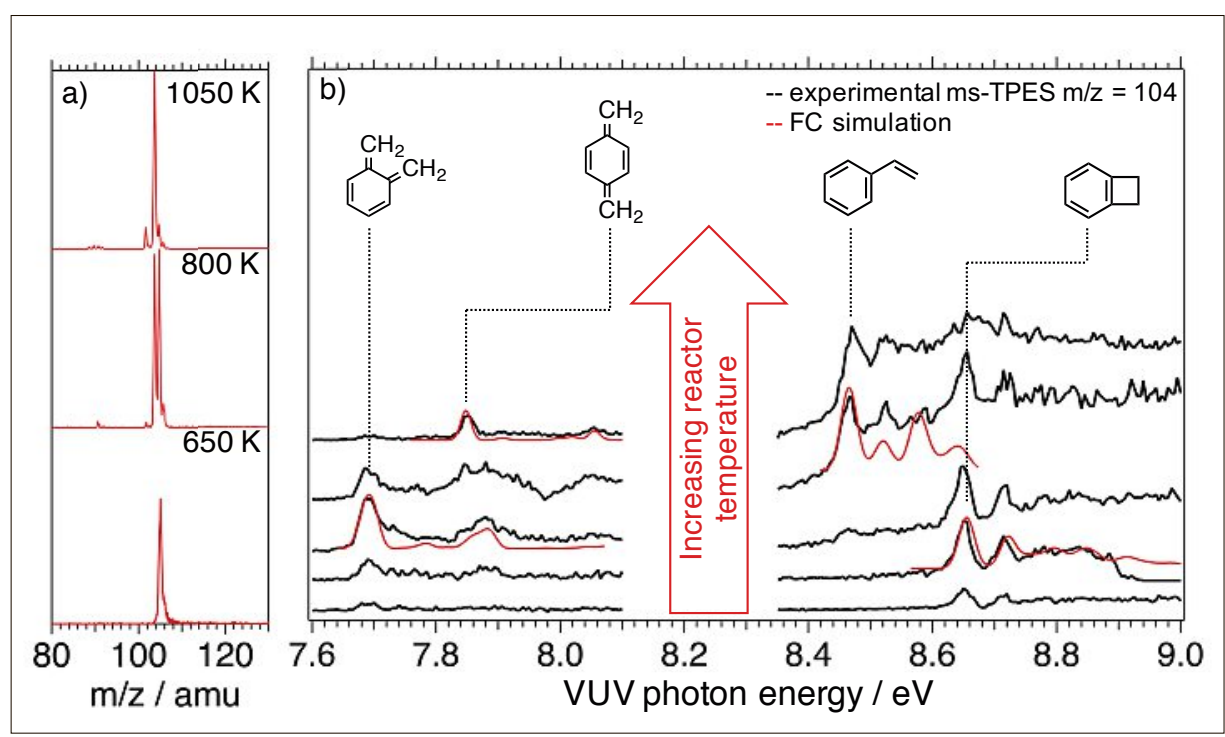

Fig. 2. a) Mass spectra showing the hydrogen atom loss from ortho-xylyl radicals $(\mathrm{m} / \mathrm{z}=105)$ at different pyrolysis reactor temperatures. b) Four isomers of the composition $\mathrm{C}_{8} \mathrm{H}_{8}(\mathrm{~m} / \mathrm{z}=104)$ can be identified as a function of the reactor temperature based on their ms-TPES. 


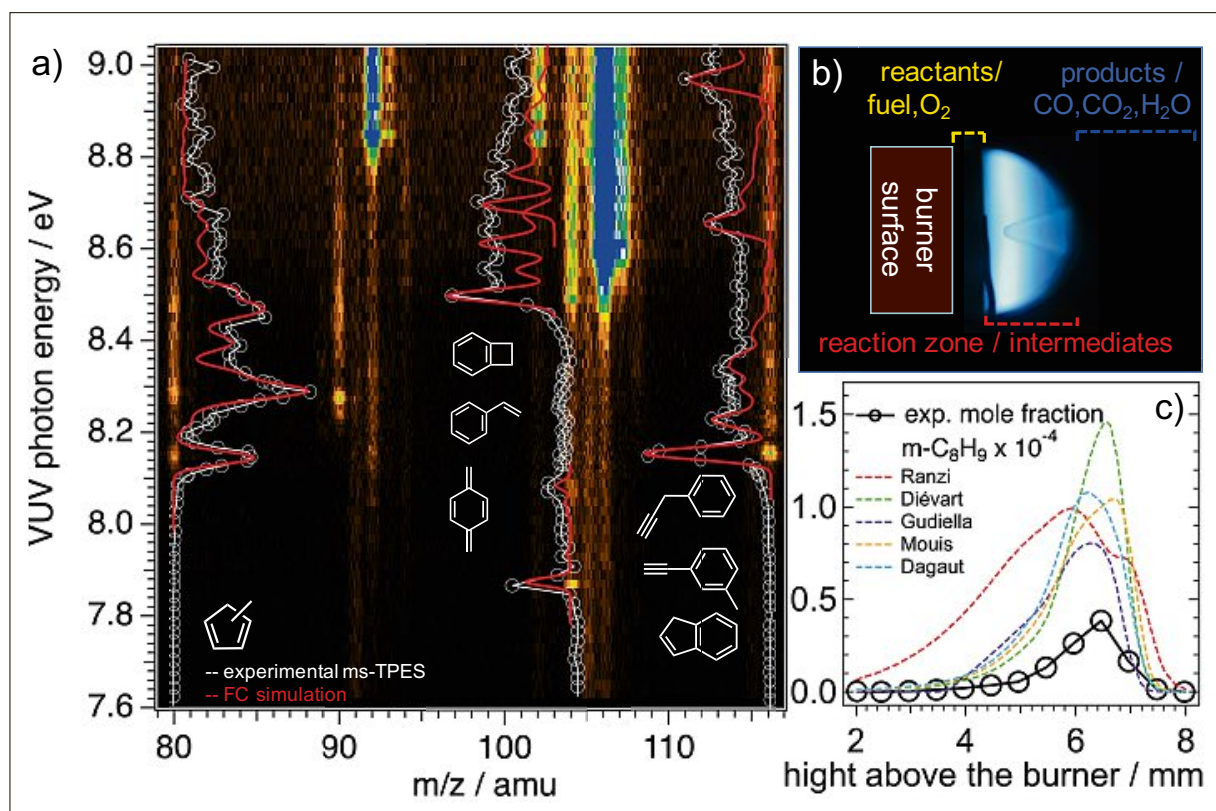

Fig. 3. a) Threshold photoionization matrix recorded in a meta-xylene/oxygen/argon flame at a stoichiometry of 1.79. Bright spots correspond to strong FC allowed transitions of specific isomers. Photoion mass-selected TPE spectra can be obtained by integrating a specific mass-tocharge ratio. Methyl-cyclopentadienes $(\mathrm{m} / \mathrm{z}=80), p$-xylylene, styrene, benzocyclobutene $(\mathrm{m} / \mathrm{z}$ $=104)$, indene, $m$-methyl-phenylacetylene and 3-phenylpropyne $(\mathrm{m} / \mathrm{z}=116)$ can be identified by their respective ms-TPE spectra (white open circles) and calculated FC factors (red lines). b) Picture of the flame and sampling cone. By varying the distance of the sampling cone to the burner surface different flame regions (reactants, intermediates and products) can be probed. c) Flame profile of meta-xylyl together with five different kinetic models, which overestimate the concentration of the radical species.

hydrocarbons (PAHs), the precursors of soot. Upon combustion of $m$-xylene, we identify three different methyl-cyclopentadiene $\left(\mathrm{c}-\mathrm{C}_{6} \mathrm{H}_{8}\right)$ isomers (Fig. 3a, left trace), which are prototypical PAH precursors together with 3-phenylpropyne, m-methylphenylacetylene and indene, and provide valuable clues to soot formation pathways.

To summarize, pyrolysis experiments ${ }^{[23,24 b]}$ yield insights into electronic and vibrational spectra and unimolecular decomposition of the xylyl radicals, which help understand the fuel destruction pathways in xylene flames. ${ }^{[29]}$ This shows that the combination of pyrolysis and flame experiments is a powerful tool to evaluate and develop predictive kinetic models with the goal to make combustion economically and ecologically more viable.

\section{Catalysis}

In addition to more efficient combustion thanks to advanced engineering concepts and predictive kinetic models, the use of sustainable and $\mathrm{CO}_{2}$-neutral fuels is a further approach to mitigate the environmental cost of energy production. Catalytic fast pyrolysis (CFP) of biomass, e.g. waste plant material, stands out as one of the most promising techniques. ${ }^{[32]}$ Besides cellulose and hemicellulose, lignin is the third major component in bio- mass, containing phenolic, alkyloxy and aryloxy subunits. This makes it ideally suited for the production of gasoline and valuable precursors for the chemical and pharmaceutical industry. ${ }^{[33]}$ Efficient lignin depolymerization and deoxygenation techniques, e.g. by catalytic fast pyrolysis (CFP), would therefore be of value. ${ }^{[34]}$ The first step involves depolymerizing the lignin macromolecule to phenolic subunits, such as guaiacol (2-methoxyphenol). They are then further pyrolyzed on porous zeolite catalysts. CFP has only been tested in a few pilot-plants, ${ }^{[35]}$ and the technical difficulties had been underestimated, in part because the fundamental chemical processes are not fully understood. This often results in low selectivity and unsatisfactory conversion.

We think that identifying the reactive intermediates and understanding the reaction mechanisms are key to optimizing these processes, especially if 'cookand-look' strategies fail. Guaiacol represents most of the functionalities in lignin and thus serves as model compound. ${ }^{\text {[b] }}$ The underlying chemistry on the catalyst surface can be resolved by sensitive and isomer-specific detection of elusive species. Surface intermediates are difficult to identify in situ due to spectral congestion $^{[36]}$ and, even if they are desorbed from the surface to some extent, standard chemical analysis tools, e.g. gas chromatography coupled with mass spectrometry (GC/MS) are too slow to identify them due to rapid quenching prior to detection.

We have developed a novel system, which combines a catalytic reactor (see Fig. 4a) with the PEPICO detection technique ( $p y$-iPEPICO). Guaiacol was highly diluted in an inert carrier gas (Ar) and pulsed into a zeolite-catalyst (HUSY) coated quartz glass reactor held at $400-500{ }^{\circ} \mathrm{C}$. The products and intermediates desorbed from the catalyst surface are ionized using VUV radiation and detected by PEPICO. Due to the low pressure $(<0.5$ mbar) in the reactor and fast expansion into high vacuum, gas-phase reactive intermediates are preserved and detected. In addition to unveiling the mechanism based on the isomer-specific identification of the desorbed species, time-on-stream (tos) curves can also be recorded by py-iPEPICO and yield insights into the temporal evolution of the state of the catalyst, its activity and the desorption processes. This approach introduces a pressure gap to ambient pressure CFP. To bridge it, we have also conducted experiments in a commercial pyrolysis gas chromatography mass spectrometry setup (py-GC/MS, see Fig. 4b) and observed the same stable reaction products: phenol $(\mathrm{m} / \mathrm{z}=94, \mathbf{2 1})$, anisole $(\mathbf{2 3}, \mathrm{m} / \mathrm{z}=108)$ and cresols $(\mathbf{2 2}$, methyl-phenols, $m / z=108)$ in both setups. However, the intermediates fulvenone $(\mathbf{1 3}, \mathrm{m} / \mathrm{z}=92)$, (methyl-)cyclopentadiene (16 and 17 at $\mathrm{m} / \mathrm{z}=66$ and 80) and fulvene $(\mathbf{1 8}, \mathrm{m} / \mathrm{z}=78)$ were only observed in the py-iPEPICO setup (see Scheme 2). While benzene (19) was found as the sole $\mathrm{C}_{6} \mathrm{H}_{6}$ isomer in the py-GC/MS experiments, we also identified fulvene $\left(c-\mathrm{C}_{5} \mathrm{H}_{4}=\mathrm{CH}_{2}, \mathbf{1 8}\right)$ at $\mathrm{m} / \mathrm{z}=78$ in the pyiPEPICO setup. This confirms fulvene as the reactive intermediate upon benzene formation, as speculated previously in the literature. ${ }^{[37]}$

Based on the py-iPEPICO results, we can establish the reaction mechanism of the zeolite-catalyzed fast pyrolysis of guaiacol as summarized in Scheme 2: After demethylation of guaiacol $(\mathbf{1 1}, \mathrm{m} / \mathrm{z}=124)$, catechol $(\mathbf{1 2}, 1,2$-benzenediol, $m / z=108)$ is formed in a transmethylation reaction. Transmethylation can be suppressed by pyrolyzing pure catechol, in which case $\mathrm{CO}$, $\mathrm{CO}_{2}$, phenol (21), cyclopentadiene (16) and fulvenone (13) were only observed, as seen in the tos curve in Fig. 4c. The central intermediate fulvenone (13) is formed in a Brønsted acid catalyzed dehydration reaction $(\mathbf{1 2} \rightarrow \mathbf{1 3})$, as evidenced by the suppression of fulvenone in the absence of Brønsted acid sites on the catalyst. We also found that hydride/hydrogen transfer reactions from coke or highly condensed polyaromatics (produced as side products upon CFP) are responsible for the formation of phenol (21) and cyclopentadiene 


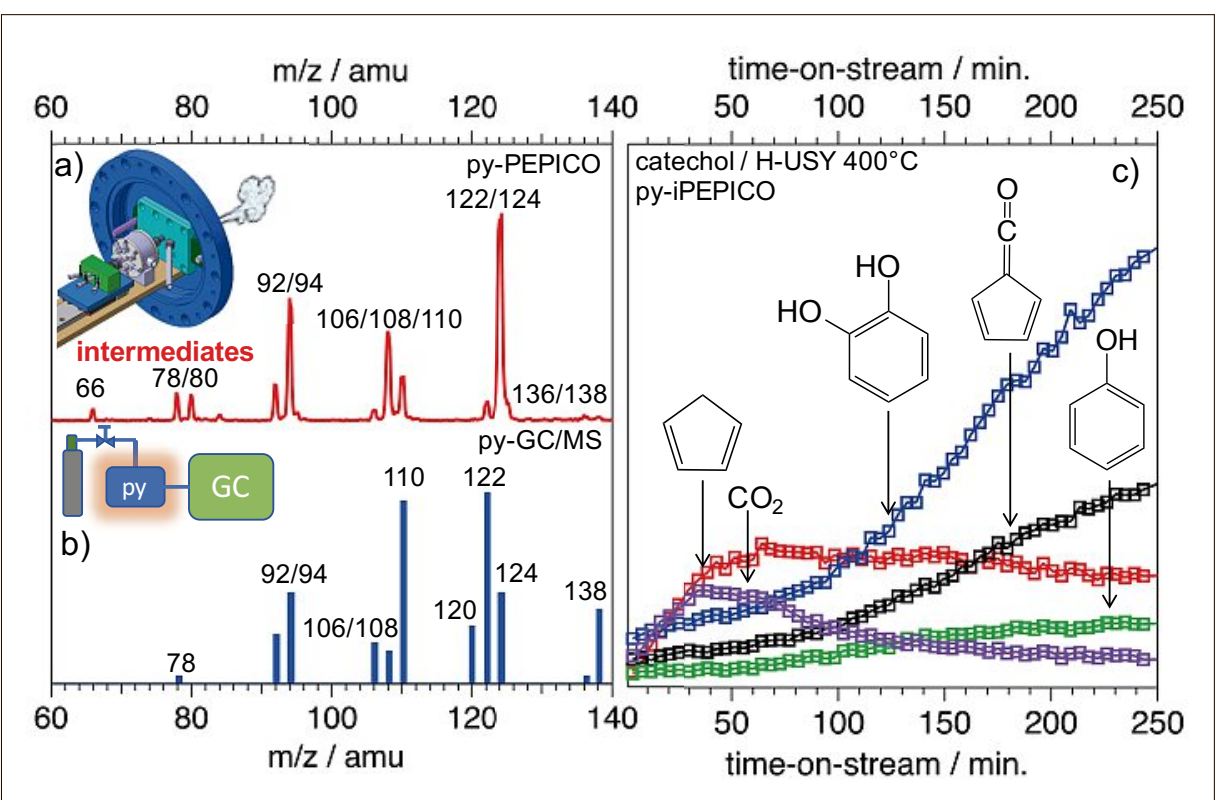

Fig. 4. Mass spectra of the catalytic fast pyrolysis of guaiacol in a) our py-iPEPICO setup and b) in a conventinal pyrolysis gas chromatography/mass spectrometry setup (py-GC/MS). While both setups yield the same final products, we identify lighter and more reactive species in the pyiPEPICO setup exclusively. A time-on-stream curve (c) shows time-dependent traces of intermediates and products of a pure catechol sample over an HUSY zeolite catalyst.

(16) from fulvenone. The phenoxy radical (15) is formed after hydrogen atom addition to fulvenone and is stabilized by a second hydrogen transfer to yield phenol. Alternatively, the $\mathrm{C}_{6} \mathrm{H}_{5} \mathrm{O}$ adduct loses $\mathrm{CO}$ to form cyclopentadienyl $\left(\mathbf{1 4}, c-\mathrm{C}_{5} \mathrm{H}_{5}\right)$ and stabilizes to yield cyclopentadiene (16). Fulvenone was thus found to be the missing central reactive intermediate in the deoxygenation reaction of lignin model compounds. ${ }^{[38]}$ This reaction is essential to upgrading lignin to fuel and gasoline, where a low oxygen content is generally imperative. Furthermore, ${ }^{13} \mathrm{C}$-labeling of the methoxy functionality of guaiacol (11, see orange asterisk in Scheme 2) helped to follow the fate of the methyl group and to complete the reaction mechanism. Benzene can be formed either by methylation of cyclopentadiene (16) over fulvene (18) or by dehydration of phenol $(\mathbf{2 1} \rightarrow$ 19). Transmethylation is responsible for cresols (22), anisole (21) and methyl-cyclopentadiene (17) formation.

Although guaiacol is a comparatively small molecule, it already follows a complex chemistry upon CFP, and we believe that the detailed understanding of these mechanisms is needed to optimize this process for large-scale industrial use. Our technique can provide valuable insights into reaction mechanisms in heterogeneously catalyzed reactions and constitutes an excellent extension to surface sensitive detection methods. ${ }^{7 b]}$

\section{Conclusion}

Reactive intermediates drive chemical reactions in combustion processes and in heterogeneous catalysis. Identifying them amounts to unveiling the reaction mechanism. In this work, we show by using a combination of mass spectrometry and photoelectron spectroscopy with VUV radiation that elusive species can be isomer-selectively detected in the gas phase. Such an approach helped establish the unimolecular decay mechanism of $o$-xylyl radicals in pyrolysis reactors to form e.g. $o$-xylylene at low temperatures and styrene at elevated ones. Second, these insights could be called upon in rationalizing model flame experiments, in which the $m$-xylyl mole fraction was found to be much below the value predicted by models in which the isomerization channel is not included. We argue that such observations will help develop and improve predictive combustion models. Third, studying the gas phase fraction desorbed from the catalyst surface in the catalytic fast pyrolysis of guaiacol by py-iPEPICO revealed fulvenone ketene as the central reactive intermediate in the deoxygenation reaction. Control experiments without a mobile methyl group, isotope labeling and Brønsted acid site suppression supported the proposed CFP mechanism. These two examples illustrate how PEPICO contributes to our understanding of complex reactive mixtures as an analytical tool. Future work will build on the inherent $\mu$ s time resolution of the approach to study the kinetics of bimolecular reactions as well as include new reactors and sampling interfaces from up to ambient pressure to broaden the spectrum of accessible reactive environments to analyze.

\section{Acknowledgements}

We acknowledge funding by the Swiss Federal Office of Energy (BFE) under contract number SI/501269-01, and thank Patrick Ascher for technical support. Experiments were carried out at the VUV beamline at Swiss Light Source, Paul Scherrer Institute. We are grateful to Dr. Markus Köhler and Thomas Bierkandt for providing the photo of the flame (Fig. 3b) and the experimental data (Fig. 3c).

Received: January 24, 2018

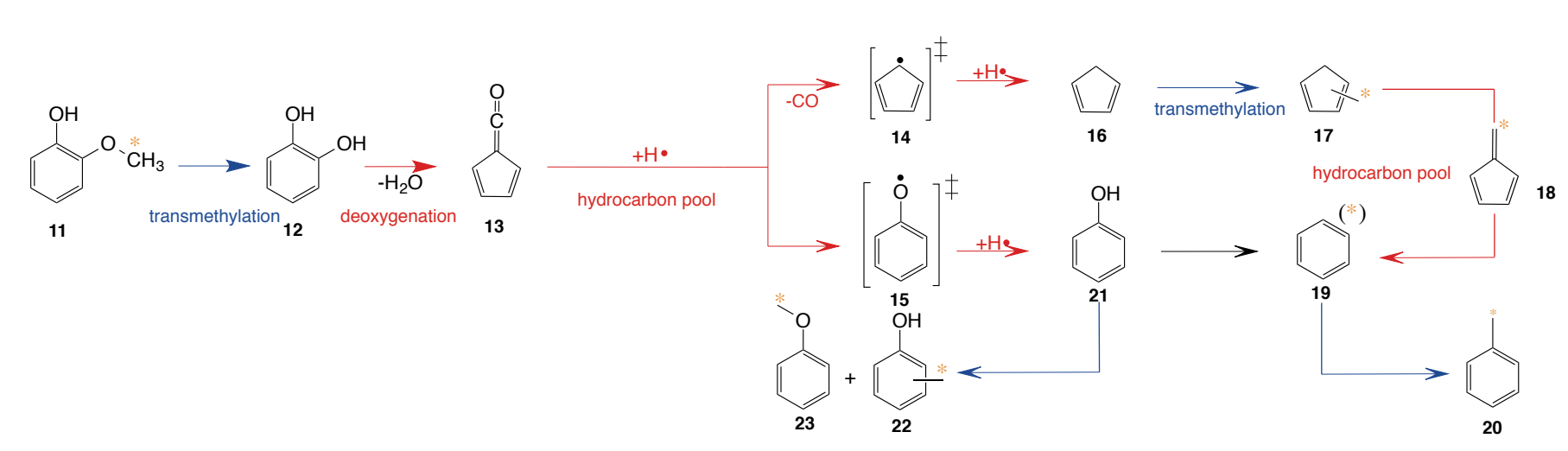

Scheme 2. Reaction mechasnism of the catalytic fast pyrolysis of guaicaol over a HUSY zeolite catalyst. 
[1] 'Schweizerische Gesamtenergiestatistik 2016 , http://www.bfe.admin.ch/themen/00526/ 00541/00542/00631/index.html?lang= de\&dossier id $=00763,2016$.

[2] A. Brockhinke, M. Letzgus, K. KohseHöinghaus, ZiF-Mitteilungen 2017, 3, 19.

[3] M. D. Morse, Exp. Meth. Phys. Sci. 1996, 29, 21.

[4] a) J. D. Savee, E. Papajak, B. Rotavera, H. Huang, A. J. Eskola, O. Welz, L. Sheps, C. A. Taatjes, J. Zádor, D. L. Osborn, Science 2015 347, 643; b) Y. Li, F. Qi, Acc. Chem. Res. 2010, 43,68 .

[5] a) C. A. Taatjes, N. Hansen, D. L. Osborn, K. Kohse-Hoinghaus, T. A. Cool, P. R Westmoreland, Phys. Chem. Chem. Phys. 2008 10, 20; b) D. Felsmann, K. Moshammer, J. Kruger, A. Lackner, A. Brockhinke, T. Kasper, T. Bierkandt, E. Akyildiz, N. Hansen, A. Lucassen, P. Osswald, M. Kohler, G. A. Garcia, L. Nahon, P. Hemberger, A. Bodi, T. Gerber, K Kohse-Hoinghaus, P. Combust. Inst. 2015, 35, 779 .

[6] a) O. Welz, J. D. Savee, D. L. Osborn, S. S. Vasu, C. J. Percival, D. E. Shallcross, C. A. Taatjes, Science 2012, 335, 204; b) P. Hemberger, G. da Silva, A. J. Trevitt, T. Gerber, A. Bodi, Phys. Chem. Chem. Phys. 2015, 17, 30076.

[7] a) F. Jiao, J. Li, X. Pan, J. Xiao, H. Li, H. Ma M. Wei, Y. Pan, Z. Zhou, M. Li, S. Miao, J. Li, Y. Zhu, D. Xiao, T. He, J. Yang, F. Qi, Q. Fu, X. Bao, Science 2016, 351, 1065; b) P. Hemberger, V. B. F. Custodis, A. Bodi, T. Gerber, J. A. van Bokhoven, Nat. Commun. 2017, 8, 15946; c) Y Li, X. Zhang, H. He, Y. Yu, T. Yuan, Z. Tian, J. Wang, Y. Li, Appl. Catal., B. 2009, 89, 659; d) L. Luo, X. Tang, W. Wang, Y. Wang, S. Sun, F Qi, W. Huang, Sci. Rep. 2013, 3, 1625.

[8] B. Brehm, E. v. Puttkamer, Z. Naturforsch. 1967, 22, 8 .

[9] T. Baer, R. P. Tuckett, Phys. Chem. Chem. Phys. 2017, 19, 9698.

[10] a) A. Bodi, P. Hemberger, T. Gerber, B. Sztáray, Rev. Sci. Instrum. 2012, 83, 083105; b) G. A. Garcia, L. Nahon, S. Daly, I. Powis, Nat. Commun. 2013, 4, 2132; c) B. Sztáray, K. Voronova, K. G. Torma, K. J. Covert, A Bodi, P. Hemberger, T. Gerber, D. L. Osborn, $J$. Chem. Phys. 2017, 147, 013944; d) X. Tang, X. Zhou, M. Niu, S. Liu, J. Sun, X. Shan, F. Liu, L. Sheng, Rev. Sci. Instrum. 2009, 80, 113101.

[11] a) A. Bodi, J. Csontos, M. Kallay, S. Borkar, B. Sztaray, Chem. Sci. 2014, 5, 3057; b) B Sztáray, A. Bodi, T. Baer, Int. J. Mass Spectrom. 2010, 45, 1233.

[12] a) P. Hemberger, A. Bodi, T. Gerber, M Würtemberger, U. Radius, Chem. Eur. J. 2013, 19, 7090; b) A. Bodi, P. Hemberger, R. P. Tuckett, Phys. Chem. Chem. Phys. 2017, 19, 30173.

[13] a) T. Schüßler, H. J. Deyerl, S. Dümmler, I. Fischer, C. Alcaraz, M. Elhanine, J. Chem. Phys. 2003, 118, 9077; b) T. Schüßler, W. Roth, T. Gerber, C. Alcaraz, I. Fischer, Phys. Chem. Chem. Phys. 2005, 7, 819.
[14] a) P. Hemberger, M. Steinbauer, M. Schneider, I. Fischer, M. Johnson, A. Bodi, T. Gerber, J. Phys. Chem. A 2010, 114, 4698; b) F. Holzmeier, M. Lang, I. Fischer, P. Hemberger, G. A. Garcia, X. Tang, J. C. Loison, Phys. Chem. Chem. Phys. 2015, 17, 19507; c) F. Holzmeier, I. Wagner, I. Fischer, A. Bodi, P. Hemberger, J. Phys. Chem. A 2016, 120, 4702 d) T. K. Ormond, P. Hemberger, T. P. Troy, M Ahmed, J. F. Stanton, G. B. Ellison, Mol. Phys. 2015, 113, 2350; e) J. D. Savee, J. Zádor, P. Hemberger, B. Sztáray, A. Bodi, D. L. Osborn, Mol. Phys. 2015, 113, 2217; f) M. Steinbauer, P. Hemberger, I. Fischer, A. Bodi, Chem. Phys. Chem. 2011, 12, 1795.

[15] a) M. Steglich, V. B. F. Custodis, A. J. Trevitt, G. daSilva, A. Bodi, P. Hemberger, J. Am Chem. Soc. 2017, 139, 14348; b) P. Neuhaus, D. Grote, W. Sander, J. Am. Chem. Soc. 2008, 130 , 2993.

[16] K. Voronova, K. M. Ervin, K. G. Torma, P. Hemberger, A. Bodi, T. Gerber, D. L. Osborn, B. Sztáray, J. Phys. Chem. Lett. 2017, 534

[17] a) D. L. Osborn, C. C. Hayden, P. Hemberger, A. Bodi, K. Voronova, B. Sztáray, J. Chem. Phys 2016, 145, 164202; b) A. Bodi, P. Hemberger, D. L. Osborn, B. Sztáray, J. Phys. Chem. Lett. 2013, 4, 2948

[18] a) S. Liang, P. Hemberger, N. M. Neisius, A. Bodi, H. Grützmacher, J. LevaloisGrützmacher, S. Gaan, Chem. Eur. J. 2015, 21, 1073; b) S. Liang, P. Hemberger, J. LevaloisGrützmacher, H. Grützmacher, S. Gaan, Chem. Eur. J. 2017, 23, 5595; c) J. Bouwman, A. Bodi, J. Oomens, P. Hemberger, Phys. Chem. Chem. Phys. 2015, 17, 20508; d) J. I. M. Pastoors, A. Bodi, P. Hemberger, J. Bouwman, Chem. Eur. J. 2017, 23, 13131.

[19] U. EPA, 2009.

[20] I. Da Costa, R. A. Eng, A. Gebert, H. Hippler, $P$ Combust. Inst. 2000, 28, 1537

[21] R. X. Fernandes, A. Gebert, H. Hippler, $P$. Combust. Inst. 2002, 29, 1337.

[22] a) D. W. Kohn, H. Clauberg, P. Chen, Rev. Sci. Instrum. 1992, 63, 4003; b) Q. Guan, K. N Urness, T. K. Ormond, D. E. David, G. Barney Ellison, J. W. Daily, Int. Rev. Phys. Chem. 2014, $33,447$.

[23] P. Hemberger, A. J. Trevitt, T. Gerber, E. Ross, G. da Silva, J. Phys. Chem. A 2014, 118, 3593.

[24] a) K. Pachner, M. Steglich, P. Hemberger, I. Fischer, J. Chem. Phys. 2017, 147, 084303; b) P. Hemberger, A. J. Trevitt, E. Ross, G. da Silva, J. Phys. Chem. Lett. 2013, 4, 2546.

[25] P. Osswald, P. Hemberger, T. Bierkandt, E. Akyildiz, M. Kohler, A. Bodi, T. Gerber, T. Kasper, Rev. Sci. Instrum. 2014, 85.

[26] a) K. Kohse-Höinghaus, P. Oßwald, T. A. Cool, T. Kasper, N. Hansen, F. Qi, C. K. Westbrook, P. R. Westmoreland, Angew. Chem. Int. Ed. 2010, 49, 3572; b) N. Hansen, T. A. Cool, P. R. Westmoreland, K. Kohse-Höinghaus, Prog. Energy Combust. Sci. 2009, 35, 168.

[27] J. Farrell, R. Johnston, I. Androulakis, SAE Paper 2004, 2004-01-2936.
[28] G. da Silva, E. E. Moore, J. W. Bozzelli, J. Phys. Chem. A 2009, 113, 10264.

[29] T. Bierkandt, P. Hemberger, P. Oßwald, M. Köhler, T. Kasper, P. Combust. Inst. 2017, 36, 1223.

[30] a) T. A. Cool, A. McIlroy, F. Qi, P. R. Westmoreland, L. Poisson, D. S. Peterka, M Ahmed, Rev. Sci. Instrum. 2005, 76, 094102; b) T. Kasper, U. Struckmeier, P. Oßwald, K. Kohse-Höinghaus, P. Combust. Inst. 2009, 32, 1285 ; c) P. Oßwald, H. Güldenberg, K. KohseHöinghaus, B. Yang, T. Yuan, F. Qi, Combust. Flame 2011, 158, 2; d) M. Schenk, L. Leon, K. Moshammer, P. Oßwald, T. Zeuch, L. Seidel, F. Mauss, K. Kohse-Höinghaus, Combust. Flame 2013, 160, 487 .

[31] a) S. Gaïl, P. Dagaut, Combust. Sci. Technol. 2007, 179, 813; b) S. Gudiyella, T. Malewicki, A. Comandini, K. Brezinsky, Combust. Flame 2011, 158, 687; c) A. G. Mouis, A. Menon, V. Katta, T. A. Litzinger, M. Linevsky, R. J. Santoro, S. P. Zeppieri, M. B. Colket, W. M. Roquemore, Combust. Flame 2012, 159, 3168; d) E. Ranzi, A. Frassoldati, R. Grana, A. Cuoci, T. Faravelli, A. P. Kelley, C. K. Law, Prog. Energy Combust. Sci. 2012, 38, 468; e) P. Diévart, H. H. Kim, S. H. Won, Y. Ju, F. L. Dryer, S. Dooley, W. Wang, M. A. Oehlschlaeger, Fuel 2013, 109, 125.

[32] a) C. Li, X. Zhao, A. Wang, G. W. Huber, T Zhang, Chem. Rev. 2015, 115, 11559; b) A. J. Foster, J. Jae, Y.-T. Cheng, G. W. Huber, R. F. Lobo, Appl. Catal., A 2012, 423-424, 154; c) Z. Ma, E. Troussard, J. A. van Bokhoven, Appl. Catal., A 2012, 423-424, 130; d) Z. Ma, V. Custodis, P. Hemberger, C. Bährle, F. Vogel, G. Jeschke, J. A. van Bokhoven, Chimia 2015, 69, 597.

[33] a) R. Thilakaratne, J.-P. Tessonnier, R. C. Brown, Green Chem. 2016, 18, 2231; b) T. P. Vispute, H. Zhang, A. Sanna, R. Xiao, G. W. Huber, Science 2010, 330, 1222.

[34] G. Zhou, P. A. Jensen, D. M. Le, N. O. Knudsen, A. D. Jensen, Green Chem. 2016, 18, 1965.

[35] R. H. Venderbosch, Chem. Sus. Chem. 2015, 8, 1306.

[36] S. Bordiga, E. Groppo, G. Agostini, J. A. van Bokhoven, C. Lamberti, Chem. Rev. 2013, 113, 1736.

[37] A. Fahr, A. Nayak, Int. J. Chem. Kinet. 2000, 32, 118 .

[38] a) S. Cheah, A. K. Starace, E. Gjersing, S. Bernier, S. Deutch, Top. Catal. 2016, 59, 109; b) L. Chen, J. Xin, L. Ni, H. Dong, D. Yan, X Lu, S. Zhang, Green Chem. 2016, 18, 2341; c) H. Lee, H. Kim, M. J. Yu, C. H. Ko, J.-K. Jeon, J. Jae, S. H. Park, S.-C. Jung, Y.-K. Park, Sci. Rep. 2016, 6, 28765; d) K. Lee, G. H. Gu, C. A. Mullen, A. A. Boateng, D. G. Vlachos, Chem. Sus. Chem. 2015, 8, 315; e) S. Ted Oyama, T. Onkawa, A. Takagaki, R. Kikuchi, S. Hosokai, Y. Suzuki, K. K. Bando, Top. Catal. 2015, 58, 201; f) Y. Xiao, A. Varma, ACS Sustainable Chem. Eng. 2015, 3, 2606; g) H. Zhang, Y. Wang, S. Shao, R. Xiao, Sci. Rep. 2016, 6, 37513 . 